Technical Report No. 32-889

\title{
Analysis of High Temperature Creep in Pyrolytic Carbon
}

W. V. Kotlensky

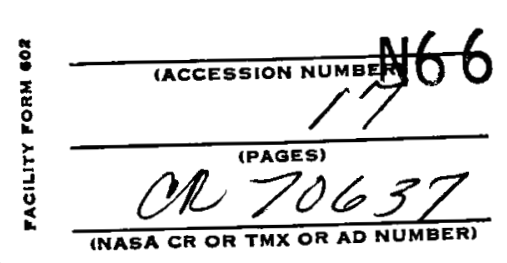

NASA $\quad$ CR70637

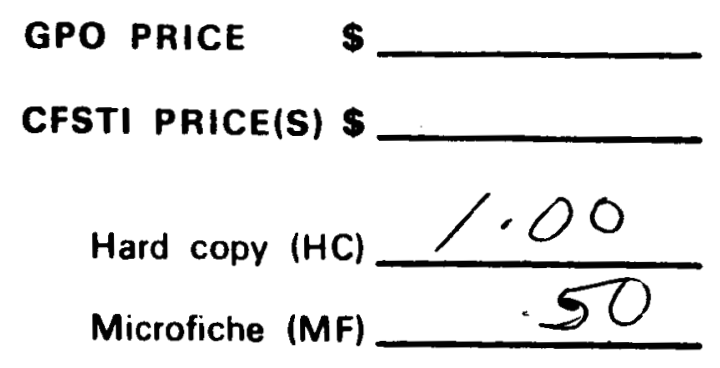

f 653 July 65

JET PROPULSION LABORATORY

CALIFORNIA INSTITUTE OF TECHNOLOGY

PASADENA. CALIFORNIA

February 15, 1966 
NATIONAL AERONAUTICS AND SPACE ADMINISTRATION

Technical Report No. 32-889

\section{Analysis of High Temperature Creep in Pyrolytic Carbon}

W. V. Kotlensky

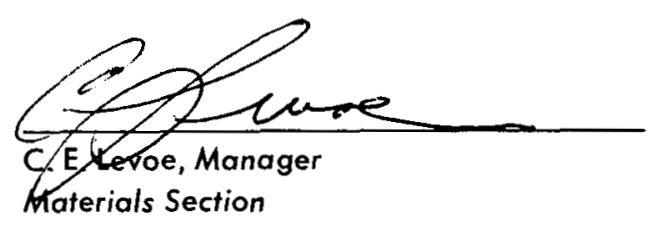

JET PROPULSION LABORATORY

CALIFORNIA INSTITUTE OF TECHNOLOGY

PASADENA. CALIFORNIA

February 15, 1966 
Copyright (C) 1966

Jet Propulsion Laboratory

California Institute of Technology

Prepared Under Contract No. NAS 7-100

National Aeronautics \& Space Administration 


\section{CONTENTS}

I. Introduction . . . . . . . . . . . . . . . . . 1

II. Experimental Materials and Procedures . . . . . . . . 2

III. Experimental Results and Analysis . . . . . . . . . . 3

IV. Discussion . . . . . . . . . . . . . . . . . . 7

v. Summary . . . . . . . . . . . . . . . . 8

References . . . . . . . . . . . . . . . . . 8

\section{FIGURES}

1. As deposited microstructures of substrate nucleafed (SN) and regeneratively nucleated (RN) pyrolytic carbons tested . . . . . . . . . $\quad .2$

2. Creep curves for pyrolytic carbon, initial stress 12,000 psi applied parallel to substrate. . . . . . . . . . . . . . . . . . . . 3

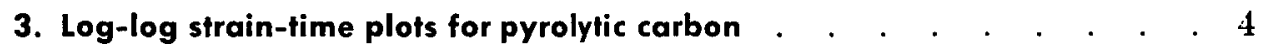

4. Creep strain as a function of temperature-compensated time. . . . . . 5

5. Microstructures of substrate nucleated (SN) pyrolytic carbon after $10 \%$ nominal creep deformation parallel to substrate at three different temperatures . . . . . . . . . . . . . 6 


\begin{abstract}
18024

Data on short-time high-temperature tensile creep parallel to the substrate for two pyrolytic carbons (pyrolytic graphites) characterized by their microstructures as substrate nucleated ( $\mathrm{SN}$ ) and regeneratively nucleated ( RN) have been analyzed by means of the Dorn method. Over the range of approximately 1.5 to $10 \%$ creep strain for the $\mathrm{SN}$ material and for creep strains above $1.5 \%$ for the $\mathrm{RN}$ material, the creep data were found to fit the empirical relationship $\epsilon=A+B t^{n}$, where $\epsilon$ is the creep strain, $t$ is the time, $n$ is a constant that depends on the material, and $A$ and $B$ are parameters that depend on both the material and the test conditions. The $\mathrm{SN}$ material was characterized by $n=0.60$, while the RN material had $n=0.42$. The same apparent activation energy of about $250 \mathrm{kcal} / \mathrm{mole}$ was calculated for both of these carbons. As assumed in the analysis, the structural change that occurs during creep was found to be dependent on the total creep strain, and the same structure was developed at a given load for the same strain, independent of test temperature. These structural changes are discussed briefly with reference to the deformation mechanisms.

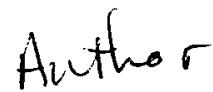

\title{
I. INTRODUCTION
}

By carefully varying the processing parameters, it is possible to produce pyrolytic carbons (pyrolytic graphites) varying in structure and properties. The two most distinguishable groups are represented by the regeneratively nucleated (RN) and the substrate nucleated (SN) classifications. These groups are easily identified by their microstructures. Polarized light photomicrographs of the edge of the basal planes show a columnar microstructure with nucleation originating at the apexes of the cones. In the $\mathrm{SN}$ classification, the growth cones are nucleated only at, or near, the substrate surface; the RN classification shows continuous cone nucleation across the thickness of the deposit. Differences in thermal expansion
(Ref. 1), strength (Ref. 2), and other properties (Refs. 3 to 5) for these two classifications have been reported.

Previous work at this Laboratory has involved tensile properties (including some preliminary creep studies), structural behavior accompanying deformation, and graphitization of these two structurally different materials (Refs. 6 and 7). As a continuation of this work, an investigation was carried out involving the short-time hightemperature tensile creep behavior parallel to the substrate in an attempt to understand more clearly the creep properties and the relationship between structure and deformation. 


\section{EXPERIMENTAL MATERIALS AND PROCEDURE}

Both of the pyrolytic carbons ${ }^{1}$ used in this study were produced at about $2100^{\circ} \mathrm{C}$ from methane gas and had the following characteristics: a density of $2.20 \mathrm{~g} / \mathrm{cm}^{3}$, a unit cell height $c_{0}$ of $6.85 \AA$, and a preferred orientation ${ }^{2}$ parameter $\beta_{1 / 2}$ of approximately 22 in the as deposited condition. However, the two samples had significantly

'SN material manufactured by High Temperature Materials, Inc.; RN material manufactured by the Raytheon Company.
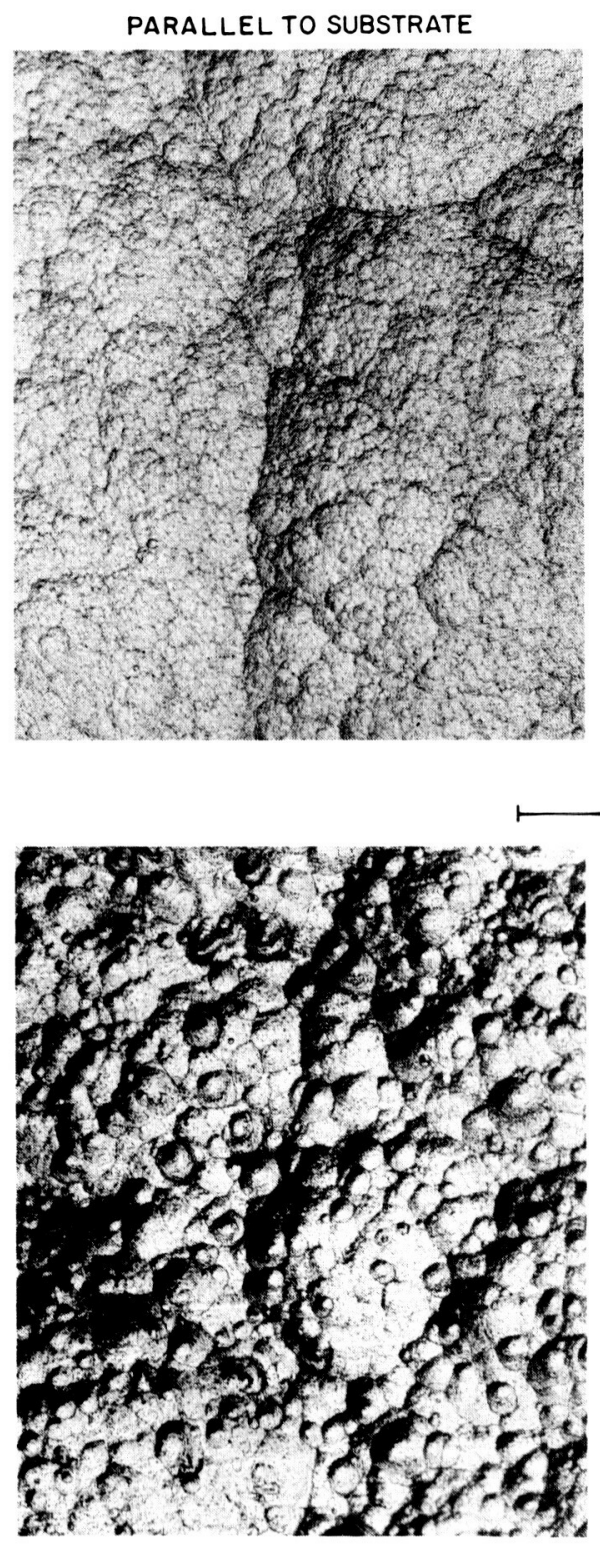

different microstructures. Polarized light photomicrographs of the as deposited carbons, parallel and perpendicular to the substrate, are shown in Fig. 1. The difference

\footnotetext{
${ }^{2}$ Measured as half-peak width at half-maximum intensity from a tracing of intensity of the (002) X-ray diffraction peak against angle of rotation about an axis parallel to the substrate plane, using small rod-shaped samples.
}

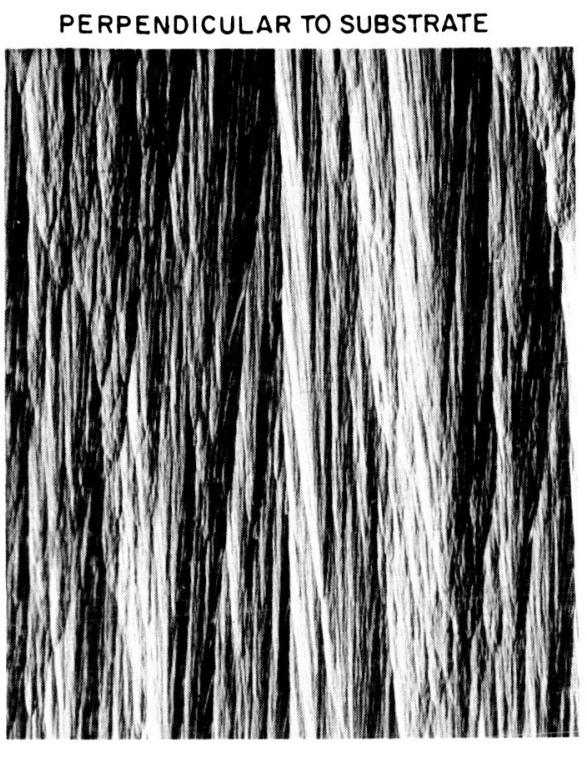

SN

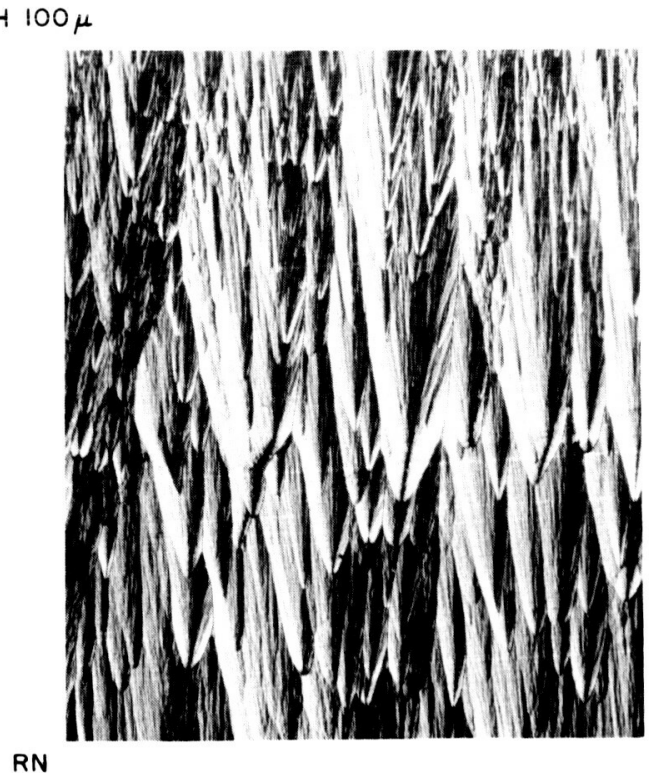

Fig. 1. As deposited microstructures of the substrate nucleated (SN) and regeneratively nucleated (RN) pyrolytic carbons tested 
in microstructure is very pronounced with the $\mathrm{RN}$ material showing the characteristic continuously nucleated cone structure, a more grainy texture and a larger angle at the apexes of the cones. Although differences in processing conditions undoubtedly account for the microstructural differences, detailed processing data were unavailable from the manufacturers.

Specimens with a $3 / 4$-in. gauge length and a $0.10-$ by 0.06 -in. cross section were machined from 3 - by 1 -in. plates that had been heat treated in $\mathrm{He}$ at $2800^{\circ} \mathrm{C}$ for $30 \mathrm{~min}$. Appreciable structural changes occur when pyrolytic carbons are heat treated at high temperatures. The $2800^{\circ} \mathrm{C}$ pretreatment was found to be sufficient to normalize the structure prior to testing so that only deformation-induced structural changes occurred during the tests. After heat treating, the two carbons still had similar X-ray diffraction structures, despite their differences in microstructure. Both materials gave the same $c_{0}$ lattice spacing of $6.75 \AA$ and the same $\beta_{1 / 2}$ of approximately 16 .

The uniaxial creep tests were made at an initial stress of 12,000 psi, which was produced by a constant load applied parallel to the substrate; the test equipment used was the same (described in Ref. 8) ${ }^{3}$ as has been used to study the creep behavior of pitch-coke graphite.

${ }^{3}$ Described also in a JPL Project Report by H. E. Martens, L. D. Jaffe, and D. D. Button, "High Temperature Short-Term Creep of Graphite," December 1958.

\section{EXPERIMENTAL RESULTS AND ANALYSIS}

Creep curves for the $\mathrm{SN}$ and RN materials are shown in Fig. 2; each of the curves has been corrected for $A$, the instantaneous strain (elastic strain, immediate plastic strain, etc.) associated with the experimental arrangement, but neither set has been corrected for strain associated with deformation in the fillets. This latter correction was not measured during this creep study; however, it was found in previous tensile studies that the deformation in the fillets is a constant factor and, therefore, does not seriously affect the analysis of the creep data. Beyond the first few miñutes for the tests at $2500^{\circ} \mathrm{C}$ and above, the SN material shows a greater time-dependent $\operatorname{strain}^{4}(\epsilon-A)$ than does the RN material. This characteristic of greater plasticity under similar conditions, which has also been observed in tensile tests (Ref. 6), results from greater strain hardening tendency in the RN material-evidently, caused by the more numerous and severe imperfections and distortions in the RN structure. As do curves from pitch-coke graphite (Ref. 8), these curves show a continuously decreasing creep rate with increasing time; there is no steady-state creep rate nor evidence of a thirdstage creep region.

An attempt was made to fit the creep curves to the empirical equation

$$
\epsilon=A+B t^{n}
$$

${ }^{4}$ Hereafter, unless otherwise noted, the term strain will refer to $(\epsilon-A)$.

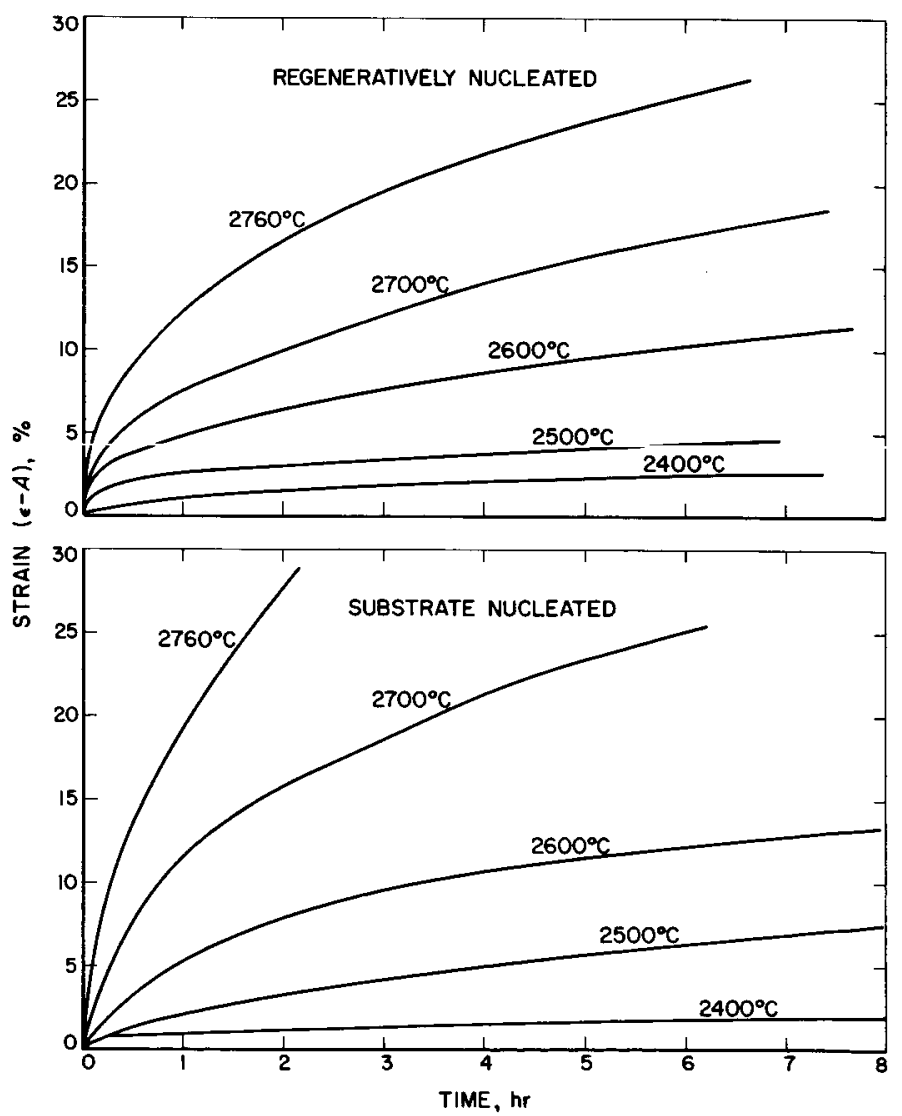

Fig. 2. Creep curves for pyrolytic carbon, initial stress 12,000 psi applied parallel to substrate 
where $\epsilon$ is the creep strain, $t$ is the time, $n$ is a constant, $B$ is a parameter dependent on stress and temperature, and $A$ is defined as above. Many metals and nonmetals obey Eq. (1) with $n$ values lying between 0.4 and 0.6 (Ref. 9). If the pyrolytic carbon creep data were to fit this equation, then a plot of $(\epsilon-A)$ vs $t$ on a $\log$-log scale should give a straight line. This analysis has been carried out, and the results are given in Fig. 3. The RN data, except for the test at $2500^{\circ} \mathrm{C}$ in which experimental difficulties were encountered, gave a family of parallel curves above $1.5 \%$ strain with an $n$ value of 0.42 . The $\mathrm{SN}$ data fit Eq. (1) over the range of approximately 1.5 to $10 \%$ strain with an $n$ value of 0.60 . The scatter in the data at low strains is attributed to lack of sensitivity in measuring small strains and to some uncertainty in estimating the instantaneous strain $A$. The departure from linearity for the SN data above approximately $10 \%$ strain is believed to be associated with the beginning of the second stage of deformation (Refs. 10 and 11) in this material. These deformation stages, which will be considered further in

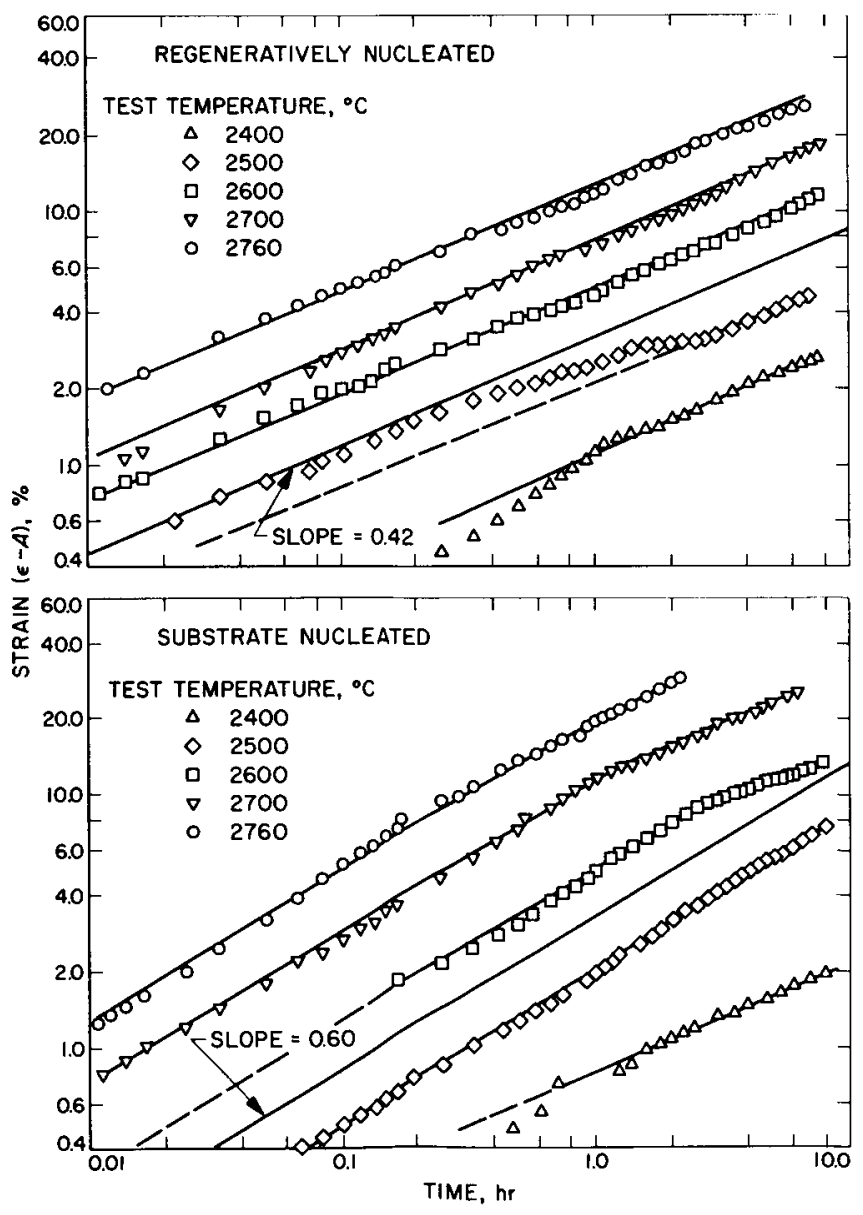

Fig. 3. Log-log strain-time plots for pyrolytic carbon
Section IV, should not be confused with the transient and steady-state stages observed in the creep of metals. Steady-state creep would cause an upward curvature on the log-log plot in Fig. 3. The significance of Fig. 3 is that both the RN and SN materials give a family of parallel curves with a reasonable fit to Eq. (1) over the specified range and that $n$ appears to depend upon the structure.

In considering the phenomenon of high-temperature creep in metals, Dorn (Ref. 12) drew the following conclusions: (1) The observed changes in creep rate with time arise from structural changes that occur during creep; the same structure is developed under a given stress or load for the same strain, independent of test temperature. (2) The creep rate is controlled by some process involving thermal activation. (3) When plotted as a function of log time, creep curves for the same stress or load are identical, except for parallel displacement along the time axis. If the Dorn method of analysis were to be applied satisfactorily to pyrolytic carbon creep, then it must be shown that these three characteristics are observed. For the sake of convenience, the latter two conditions will be considered first, since they are interrelated.

When plotted as shown in Fig. 3, the creep data for pyrolytic carbon give a reasonable set of parallel curves that are identical, except for the displacement along the time axis. Following Dorn, it is assumed that the relationship between these curves is given by

$$
\epsilon-A=f\left[t \exp \left(-\frac{\Delta H}{R T}\right)\right]
$$

where $\Delta H$ is the apparent activation energy, $R$ is the gas constant, $T$ is the absolute temperature, and $\epsilon, A$, and $t$ are defined as in Eq. (1). Then the activation energy can be calculated from the following equation:

$$
t_{1} \exp \left(-\frac{\Delta H}{R T_{1}}\right)=t_{2} \exp \left(-\frac{\Delta H}{R T_{2}}\right)
$$

where $t_{1}$ and $t_{2}$ are the times required to reach a given strain at temperatures $T_{1}$ and $T_{2}$. This calculation was made for all combinations of $t_{\mathrm{i}}$ and $T_{\mathrm{i}}$ at a strain of $2 \%$ for the two sets of curves in Fig. 3, and average apparent activation energy values of $240 \mathrm{kcal} / \mathrm{mole}$ for the SN and $260 \mathrm{kcal} / \mathrm{mole}$ for the $\mathrm{RN}$ pyrolytic carbons were obtained.

When $\Delta H$ is known, the creep data can be superimposed reasonably well onto a single curve for each material by use of Eq. (2), as shown in Fig. 4. The departure 


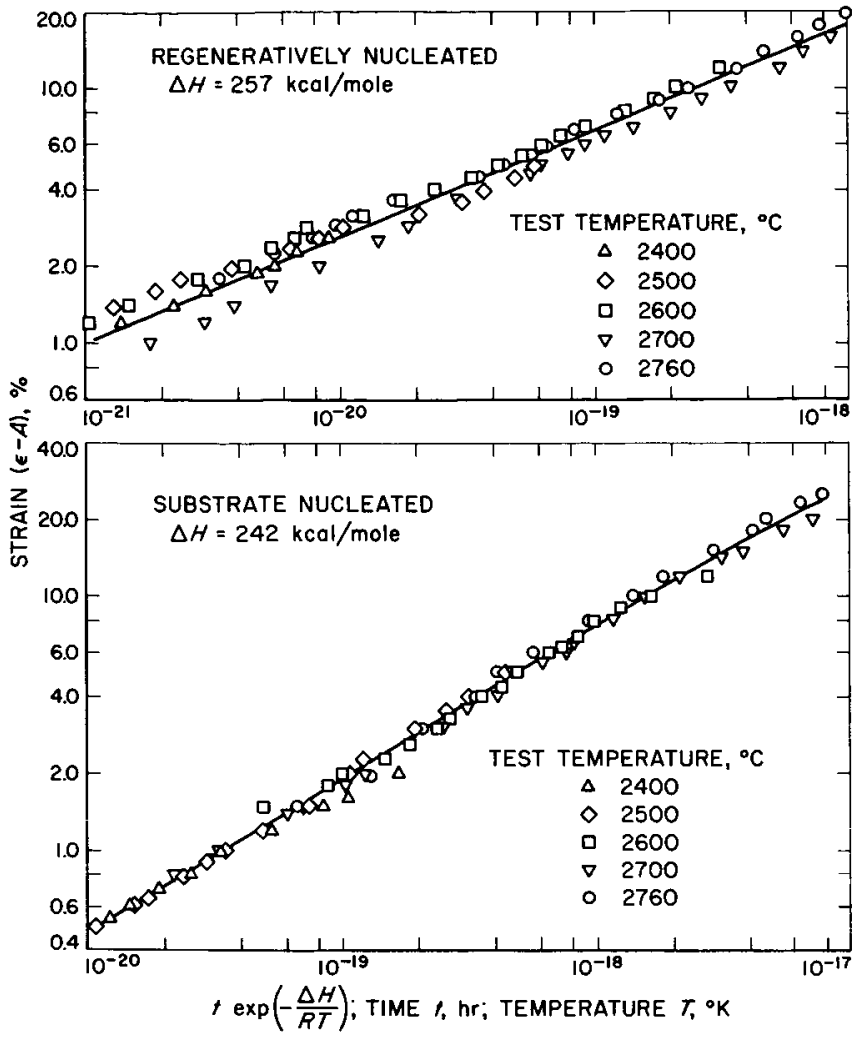

Fig. 4. Creep strain as a function of temperaturecompensated time

of the data points from the individual curves in Fig. 4 is not considered to be significant. Errors in temperature measurement, insensitivity of the strain measuring sys- tem, and errors in estimating the instantaneous strain can account for the scatter. In the $\mathrm{RN}$ material, the scatter is approximately $\pm 10 \%$ of the measured value; the scatter is somewhat less for the $\mathrm{SN}$ material.

Considering now the first condition of Dorn's analysis, it remains to be shown that the same structure is developed for the same strain during the creep deformation of pyrolytic carbon, independent of test temperature. For this part of the study, a detailed structure analysis was carried out only on the SN material. A less rigorous structure analysis on the $\mathrm{RN}$ material gave similar, although less pronounced, results.

Figure 5 shows micrographs that were taken from three orthogonal views at the center of the gauge section. These micrographs show the structures developed at three different temperatures for the same nominal $10 \%$ strain. Corresponding micrographs of comparable surfaces are indistinguishable. In addition, all three specimens shown in Fig. 5 gave the same unit cell dimcnsions, $c_{v}=6.73 \AA$ and $a_{0}=2.46 \AA$, and the same $\beta_{1 / 2}$ of $6.9 \mathrm{deg}$ and $1.8 \mathrm{deg}$ measured about axes in the substrate plane parallel and perpendicular to the stress. The structure developed by the deformation is a function of the strain. At strain levels between about 5 and $15 \%$ the structural changes are strongly anisotropic relative to the stress axis. At higher strains this anisotropy decreases. From the standpoint of the creep analysis, the significance of Fig. 5 and the X-ray data is that the Dorn condition is obeyed, i.e., the same structure is developed at the same strain, independent of test temperature. 

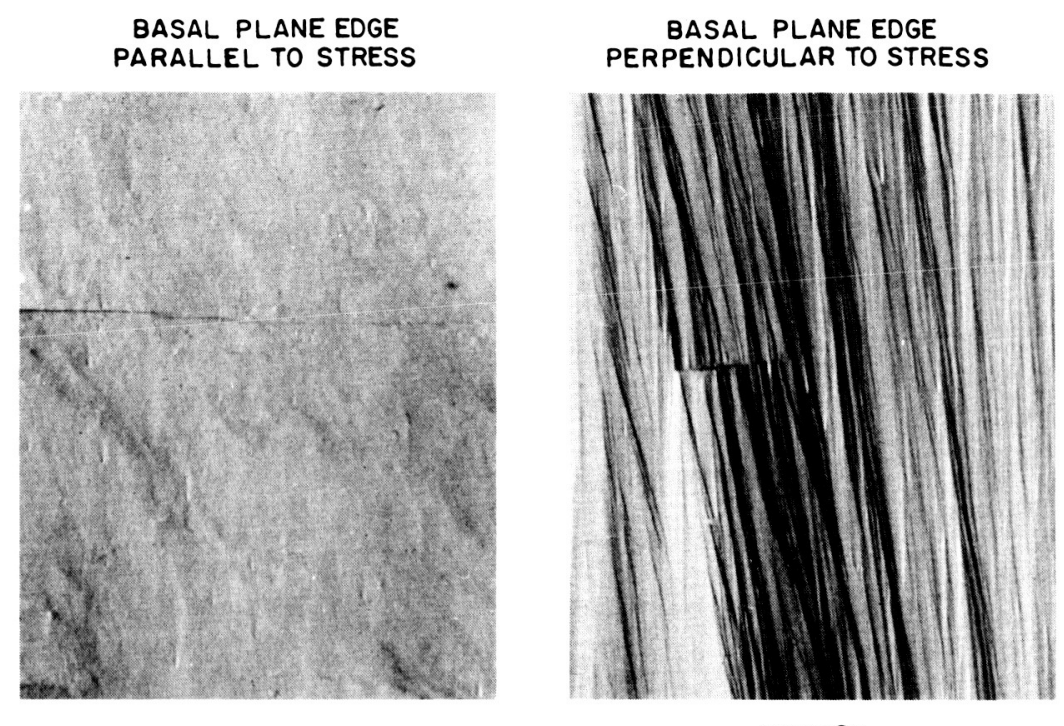

BASAL PLANE SURFACE
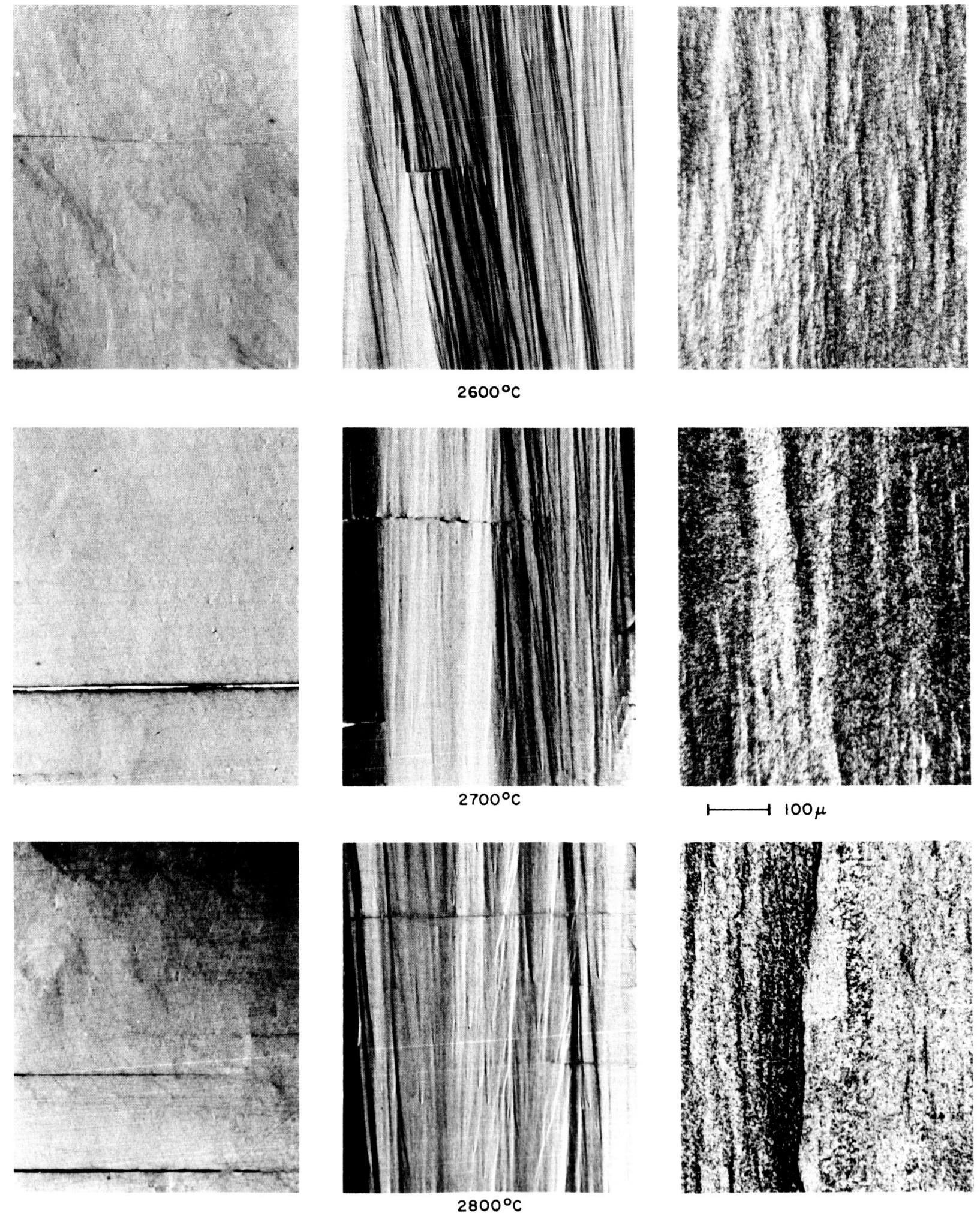

Fig. 5. Microstructures of substrate nucleated (SN) pyrolytic carbon after $10 \%$ nominal creep deformation parallel to substrate at three different temperatures 


\section{DISCUSSION}

Apparent activation energy values from 60 to 200 $\mathrm{kcal} / \mathrm{mole}$ have been reported for pitch-coke graphite creep for temperatures above $2400^{\circ} \mathrm{C}$ (Refs. 8 and 13 to 15). ${ }^{5}$ Earlier preliminary results on pyrolytic carbon creep gave activation energy values of 100 to $200 \mathrm{kcal} / \mathrm{mole}$ (Refs. 6 and 7). This wide variation is dependent on the testing procedure and the method of analysis. The method of analysis used in the current study is believed to be more satisfactory than analyses based on creep rates at constant strain levels, or on steady-state creep rates. ${ }^{6}$ Fischbach (Refs. 16 and 17 ) has reported a $\Delta H$ value of $260 \mathrm{kcal} / \mathrm{mole}$ for graphitization of pyrolytic carbons and pitch-coke carbons over the range 2200 to $3000^{\circ} \mathrm{C}$ in an inert atmosphere. Kanter (Ref. 18) has calculated an activation energy of $263 \mathrm{kcal} / \mathrm{mole}$ for diffusion in graphite by a vacancy mechanism, and $113 \mathrm{kcal} / \mathrm{mole}$ for diffusion by a direct interchange mechanism, using $170 \mathrm{kcal} / \mathrm{mole}$ as the sublimation energy for carbon and the diffusion model proposed by Dienes (Ref. 19). The agreement between the apparent activation energy for pyrolytic carbon creep and the $\Delta H$ values reported by Fischbach and calculated by Kanter may be simply fortuitous, or it may indicate the fundamental process that is involved. This process, however, is not well understood, and the creep data are insufficient to definitely establish a rate-determining mechanism. On the other hand, it is significant that creep in pyrolytic carbon can be treated as a thermally activated process and, also, that the apparent activation energy obtained is reasonable. It is also significant that the $\mathrm{SN}$ and $\mathrm{RN}$ materials, although differing widely in microstructure, give very similar apparent activation energy values.

\footnotetext{
${ }^{5}$ Also in source cited in footnote 3.

'The activation energy may also be determined from $B$ in Eq. (1) if the correct functional form of $B$ is used. By use of Eq. (2), it can be shown that $B=f[\exp (-n \Delta H / R T)]$. In Ref. 9, it was incorrectly assumed that $B=f[\exp (-\Delta H / R T)]$; the $\Delta H$ values obtained there from $B$ should be multiplied by $2(n \simeq 0.5)$ to get the correct value.
}

Examination of the curves in Fig. 3 reveals that the RN curve is linear over the entire range of reliable data and that the $\mathrm{SN}$ curve is not linear beyond approximately $10 \%$ strain. As mentioned before, this break in the SN curves has been interpreted as indicating the transition from the first to the second stage of deformation (Refs. 10 and 11). The first stage of deformation in pyrolytic carbons occurs at strains less than 10 to $15 \%$; it involves dewrinkling of the initial wrinkled sheet structure, accompanied by basal plane shear. The second stage occurs at tensile elongations greater than $15 \%$ and involves deformation of very well oriented material by mechanisms which are not well understood. The differences in microstructual texture of the basal plane edge surfaces (Fig. 5) and in preferred orientation index, parallel and perpendicular to the stress, resulting from first stage deformation of the $\mathrm{SN}$ material are not too surprising and indicate that anisotropic dewrinkling has occurred. This anisotropic dewrinkling phenomenon is consistent with magnetic susceptibility measurements on deformed gauge section samples (Ref. 20) and is what would be expected based upon the reported change in gauge section width and thickness with deformation (Ref. 10). It was first noted (in preferred orientation data) by Stover (Ref. 3) that a tensile stress tends to align the basal planes parallel to the stress axis.

The lack of a similar change in slope in the creep curves for the RN material implies that a single stage is involved in its deformation up to at least $30 \%$ elongation. The deformation mechanism in $\mathrm{RN}$ carbons has not been investigated in detail, but it is reasonable to assume that the mechanism involved differs from that which occurs in the first stage of $\mathrm{SN}$ carbons. The presence of soot particles and other lattice imperfections would be expected to impede or delay complete dewrinkling; this fact was confirmed by micrographic studies on the RN samples. 


\section{SUMMARY}

Differences in the creep bchavior have been observed for the structurally different substrate nucleated (SN) and regeneratively nucleated (RN) pyrolytic carbons. When the creep data are plotted as log time-dependent strain vs log time, a family of parallel curves is obtained that obey the empirical equation $\epsilon=A+B t^{n}$. The value of $n$, which appears to depend on the structure, is 0.60 for the $\mathrm{SN}$ material and 0.42 for the $\mathrm{RN}$ material. The RN data are linear over the entire strain range investigated. The $S N$ data depart from linearity above approximately $10 \%$ strain. This characteristic has been interpreted as indicating a single stage in the deformation of the $\mathrm{RN}$ material, and a two stage deformation in the SN material consistent with other observa- tions. The presence of soot particles in the $\mathrm{RN}$ material plays an important role in its deformation.

The Dorn method of analysis has been applied satisfactorily. Creep in pyrolytic carbon involves a thermally activated rate process with an apparent activation energy of approximately $250 \mathrm{kcal} / \mathrm{mole}$. The creep curves for each of the two materials, RN and SN, have been superimposed by scaling the time axis.

The same structural features are developed for the same strain, independent of temperature; but different structural features are developed at different strains.

\section{REFERENCES}

1. Pappis, J. and Blum, S. L., J. Am. Ceram Soc. 44, 592 (1961).

2. Gebhardt, J. J. and Berry, J. M., AIAA Journal 3, 302 (1965).

3. Stover, E. R., Improvement of Pyrolytic Graphite Properties by Heat-Treating and Hot-Working, Report GE-62-RL-2991, General Electric Research Laboratory, Schenectady, N.Y., May 1962.

4. Coffin, L. F., Jr., J. Am. Ceram. Soc. 47, 473 (1964).

5. Higgs, P. H., Finicle, R. L., Bobka, R. J., Seldin, E. J., and Zeitsch, K. J., Studies of Graphite Deposited by Pyrolytic Processes, Vol. XXXVII, Technical Report No. WADD TR-61-72, National Carbon Co., Division of Union Carbide, New York City, May 1964.

6. Kotlensky, W. V., Thompson, A. W., and Titus, K. H., Jr., "High-Temperature Tensile and Short-Term Creep Properties and Structural Transformations of Pyrolytic Graphite," Paper No. 6, presented at the Sixth Carbon Conference, University of Piffsburgh, June 17-21, 1963.

7. Kotlensky, W. V. and Martens, H. E., Proceedings 5th Carbon Conference, Vol. 2, Pergamon Press, London, 1963, p. 625.

8. Martens, H. E., Button, D. D., Fischbach, D. B. and Jaffe, L. D., Proceedings 4th Carbon Conference, Pergamon Press, London, 1960, p. 511.

9. Crussard, C., Revue de Metallurgie 55, 375-378 (1958). 


\section{REFERENCES (Cont'd)}

10. Kotlensky, W. V., Trans. Met. Soc. AIME 233, 830 (1965).

11. Kotlensky, W. V. and Martens, H. E., J. Am. Ceram. Soc. 48, 135 (1965).

12. Dorn, J. E., J. Mech. Phys. Solids 3, 85 (1954).

13. Seldin, E. J., Proceedings 5th Carbon Conference, Vol. 2, Pergamon Press, London (1963), p. 545; Seldin, E. J. and Draper, R. N., "Research and Development on Advanced Graphite Materials, Vol. V: Analysis of Creep and Recovery Curves for ATJ Graphite," Report WADD TR-61-72, Vol. V, National Carbon Co., Division of Union Carbide, New York City, September 1961.

14. Seldin, E. J., "Research and Development on Advanced Graphite Materials, Vol. XVIII: High Temperature Tensile Creep of Graphite," Report WADD TR-61-72, Vol. XVIII, National Carbon Co., Division of Union Carbide, New York City, July 1963.

15. Younger, A., "Characteristics of the High Temperature Mechanism of Creep and Recovery in Graphite" (Research sponsored by U.S. Dept. of Army under Contract No. DA-91-591-EUC 2629, August 1, 1962 to July 31, 1963), Technical Report CoA Note Mat. 1, Final Technical Sheet No. 1, The College of Aeronautics, Cranfield, England, August 1963.

16. Fischbach, D. B., Appl. Phys. Letters 3, 168 (1963).

17. Fischbach, D. B., Nature 200, 1281 (1963).

18. Kanter, M. A., Phys. Rev. 107, 655 (1957).

19. Dienes, G. J., J. Appl. Phys. 23, 1194 (1952).

20. Fischbach, D. B., "Effect of Plastic Deformation on Preferred Orientation of Synthetic Carbons," Space Programs Summary No. 37-27, Vol. IV, Jet Propulsion Laboratory, Pasadena, Calif., June 1964, pp. 29-31.

\section{ACKNOWLEDGMENT}

The author acknowledges the helpful discussions with D. B. Fischbach of this Laboratory during the course of this work. 